\title{
Novel Plant Growth Regulators and their Potential Uses in Agriculture
}

\author{
Ankita Mishra ${ }^{1 *}$ and Debasish Panda ${ }^{2}$ \\ ${ }^{1}$ Division of Plant Physiology, Indian Agricultural Research Institute, Pusa, New Delhi (110 012), India \\ ${ }^{2}$ Dept. of Genetics and Plant Breeding \& Crop Physiology, Institute of Agriculture, Visva-Bharati University, Sriniketan, W.B.
}

(731 236), India

Corresponding Author

Ankita Mishra

e-mail: ankitam490@gmail.com

\author{
Article History \\ Article ID: AR1830b \\ Received in 03 ${ }^{\text {rd }}$ August, 2017 \\ Received in revised form $15^{\text {th }}$ November, 2017 \\ Accepted in final form 29 $9^{\text {th }}$ November, 2017
}

\begin{abstract}
Phytohormones or plant growth regulators play a crucial role in plant growth and developmental process. Apart from the traditional plant hormones studied so far i.e., auxin, gibberellins, cytokinin, abscisic acid, and ethylene, various other biomolecules are being reported to act as hormones. Several novel plant growth regulators discovered in the recent past includes compounds like Melatonin, Serotonin, Strigolactone, Harzianolide and Karrikins. Melatonin and Serotonin which were previously studied exclusively due to their function as neurotransmitter in animals are also being reported in plants widely. These two hormones impart specific functions during biotic and abiotic stress as well as plant growth and developmental processes. On the other hand Strigolactone previously reported as germination stimulant for weed species, also has important function in plant architecture modification. Strigolactone also imparts resistance to plants during abiotic stresses i.e. drought, salinity, heavy metal stress, temperature, nutrient starvation as well as various biotic stresses. It can be used along with the major plant hormones- auxin and cytokinin to regulate organogenesis. Reports elucidating the nature of these newly discovered biomolecules, there effects on plant growth and developmental processes as well as their interaction with other traditional hormones and other organic and inorganic molecules keep open the door for further exploration. Harzianolide isolated from Trichoderma harzianum was studied for its role in plant growth and systemic resistance. These secondary metabolites of Trichoderma promote plant growth through better root development and activation of plant defense responses. Karrikins are a group of plant growth regulators found in the smoke of burning plant materials are known to stimulate the germination of seeds. This paper reviews the literature supporting evidence on different novel plant growth regulators and their potential roles in agriculture.
\end{abstract}

Keywords: Harzianolide, Karrikins, plant growth regulator, melatonin, serotonin, strigolactone

\section{Introduction}

Plant growth regulators or plant hormones are endogenous factors which play a crucial role in plant growth and developmental process. Apart from the traditional plant hormones studied so far i.e., auxin, gibberellins (GA), cytokinin (CK), abscisic acid (ABA), and ethylene, various other biomolecules are being reported which act as hormones. These are broadly known as novel plant hormones. Among these, melatonin and serotonin-previously identified in animal kingdom and studied exclusively due to their function as neurotransmitter, are also being reported in plant kingdom widely. These two hormones impart specific functions during biotic and abiotic stress as well as plant growth and developmental processes. But the mechanism lying under various physiological responses remains elusive. Transgenic approach of study has enabled the researchers to propose the probable mechanism of action of these hormones. On the other hand strigolactone (SL) previously reported as germination stimulant for weed species, also has important function in plant architecture modification. Arbuscular mycchorrizal (AM) fungi respond to their host as well as non host species by responding to this chemicals secreted by these hosts. Apart from this, SL imparts resistance to plants during abiotic stresses i.e., drought, salinity, heavy metal stress, temperature, nutrient starvation as well as various biotic stresses. It can be used along with the major plant hormones- auxin and cytokinin to regulate organogenesis. A component of smoke-karrikin, has been reported to be involved in seed germination by influencing GA/ $A B A$ ratio. Harzianolide, metabolic component of bio-control agent- Trichoderma harzianum, shows auxin like activity and influences early seedling growth. Reports elucidating the nature of these newly discovered biomolecules, there effects on plant growth and developmental processes as well as their interaction with other traditional hormones and other organic and inorganic molecules keep open the door for 
further exploration. Extensive studies on the unexplained and unexplored facts about these potential growth regulators will lead to development of various stress tolerant and improved cultivars- which is the need of present scenario.

\section{Melatonin}

Melatonin ( $\mathrm{N}$-acetyl-5-methoxytrypalmitine), a well-known animal hormone was first reported in plants during 1995 by several groups (Dubbel et al., 1995; Kolar et al., 1995; Hattori et al., 1995). It has been detected and quantified in different plant parts (shoots, laves, roots, fruits and seeds). Melatonin possesses resemblances with auxin as both have common precursors-tryptophan. There exists interrelation between both the hormones. Melatonin plays important role in reproductive development, circadian rhythm, cell protection, vegetative development as well as responses to both biotic and abiotic stresses (Arnao and Hernandez-Ruiz., 2006). In 1997, Kolar et al., reported about the presence of melatonin in chenopodium rubrum L. and also studied the effect of changes in melatonin levels in light/dark cycles of 12 hours. An increase in its concentration during night led to further experiments which concluded that biosynthesis of this hormone shows a circadian rhythm (Wolf et al., 2001). This variation of patterns among various plant species, tissues, and organs was also reported in various plant species i.e., lupin and barley (Hernandez-Ruiz and Arnao, 2008), grapes (Boccalandro HE et al., 2011), sweet cherry (Zhao et al., 2012). Melatonin biosynthesis occurred under constant light in senescent rice leaves and was nearly undetectable under constant darkness (Tan DX et al., 2007). A remarkable evidence of melatonin functioning as a stress protecting agent during reproductive development was provided by Murch and Saxena () in Hyperium perforatum L. Important effect of melatonin as membrane integrity factor and protector of cold induced apoptosis was observed during carrot cell suspension culture (Lei XY et al., 2004). Increase in level of melatonin due to oxidative stress was reported in various plants (Boccalandro HE et al., 2011; Arnao and Hernandez-Ruiz., 2009; 2013). Transgenic rice seedlings with elevated levels of melatonin were found to be more resistant to herbicide induced oxidative stress than their wild type counter parts (Park S et al., 2013). It is also reported to have protective role against UV and ozone damage (Tan DX et al., 2002; Paredes et al., 2009; Wang P et al., 2013), altering photo-oxidation of the photosynthetic system. At moderate level, it also protect chlorophyll during senescence (Wang P et al., 2012; 2013, Arnao and Hernandez-Ruiz, 2009; Sarropoulou V et al., 2012) in diversity of plant species. Yin I et al (2013) reported increases resistance to Marssonia apple blotch by exogenous melatonin application. Melatonin also act as growth promoter as auxin. A low melatonin level stimulates lateral root growth, while higher levels promote adventitious root formation. Inhibitory effect on lateral root growth at higher concentration of the hormone implies a pathway independent of auxin (Park
WJ, 2013). Various reports suggest the stimulatory effect of melatonin in cotyledon expansion (Hernandez-Ruiz, and Arnao, 2008) and hypocotyls growth (Hernandez-Ruiz, and Arnao, 2004; 2005). Microarray analysis using endogenous melatonin rich transgenic rice reported several genes that are up or down regulated by elevated molecular levels (Byeon $Y$ et al., 2013). RNA sequencing technologies paved the new pathway in the arena of melatonin research. Genomic level study about the effect of both low and high levels of the hormone concluded about the involvement of different categories of genes responding differently to both the levels. Transcript levels of many stress receptors were up-regulated. Most identified genes in ABA, ethylene, salicylic acid, and jasmonic acid pathways were up-regulated (Weeda et al., 2014). Various reports about critical role of melatonin in plant defense against both biotic and abiotic stresses need further exploration. Further dissection of the melatonin mediated pathways, its relation with photoperiodicity, apical dominance, tropism (photo, geo and others) may lead towards the novel strategies of crop improvement.

\section{Serotonin}

Like melatonin, serotonin (5- hydroxytryptamine) was also discovered as animal hormone. Its presence in plant was reported during 1954 in medicinal plant- cowhage( Mucunapruriens) (Whitaker-Azmitia PM, 1999). Biosynthesis of this hormone involves tryptophan. Tryptophan is decarboxylated by the enzyme tryptophan decarboxylase (TDC), which gives rise to another bioactive compound tryptamine. In plants, modification in TDC- the rate limiting enzyme, influences the serotonin levels (Erland et al., 2017). In vegetative tissues of plants, the serotonin level was found to be highest (Engstron K et al., 1999; Ramakrishna A et al., 2012; Turi CE et al., 2013) , but reproductive tissues i.e flower, nut, and fruits possess higher level than vegetative tissues (Grosse W et al., 183; Lavizzari A et al., 2006; Ly D et al., 2008). Serotonin in involved in vegetative growth and morphogenesis of the plant i.e promoting shoot production, growth, and multiplication, biomass accumulation, delay in senescence, seed germination, and somatic embryogenesis (Erland LAE et al., 2015). Exogenous application of serotonin in Hypericum

perforatum L. and Mimosa pudica L. led to increase in shoot growth and application of mammalian inhibitor of serotonin reduced the effect (Murch et al., 2001, 2004: Ramakrishna A et al., 2009). Its positive effect on root growth was also reported in walnut, mimosa, sunflower, barley- suggesting its possible interaction with auxin in regulating the same (Csaba G et al., 1982; Pelagio- Flores R et al., 2011; Gatineau F et al., 1997). Variation in serotonin level was also found in different stages of seed development in walnut and it accumulated in cotyledon upon abscission (Grosse W et al., 1983, 2011; Lembeck F et al., 1984). Role of this hormone was also reported in modulating microspore development 
by interacting with CAMP signaling pathway (Erland et al., 2017). It causes overall increase in seedling biomass by influencing seed germination, coleoptiles weight, and hypocotyls elongation (Csaba G et al., 1982; Mukherjee S et al., 2014; Roschina, V.V., 2001). Though the role of serotonin in regulation flowering and reproductive development in several species along with gamete compatibility has been reported, the idea about the happening of these processes remains unclear (Erland et al., 2017). It plays pathogen specific role regarding plant defense responses and influences other downstream processes including programmed cell death and free radical scavenging. It may also play in long distance and rapid signaling response during pathogen attack (Erland et al., 2017). The ability of serotonin in mediating influx of ions into chloroplast suggests its capacity to increase survival rate during salinity stress (Pickles VR et al., 1955; Roschina VV, 1990). The high capacity of serotonin to bind with cadmium was supported by the up-regulation of its biosynthesis enzyme TDC upon cadmium treatment in rice (Byeon $Y$ et al., 2015). Lee and Back (2017) reported that overexpression of serotonin $\mathrm{N}$ acetyltransferase 1 in rice confers resistance to cadmium stress and senescence. It also increases the grain yield. It plays an important role in response to light in modern plants as well regulates circadian and seasonal rhythms. The ubiquitous distribution of this hormone in nature suggests its important role during evolution (Erland LAE et al., 2016).

\section{Strigolactone}

Strigolactone (SL) group of compounds were first discovered as growth stimulant compounds for weed species Strigalutea. Lour, from root exudates of a false host- cotton (Cook et al., 1966). Later it was found to be distributed in Striga host i.e., sorghum, maize, proso millet (Siame et al., 1993; Hauck et al., 1992; Muller et al., 1992). Another weed species Orobranche was also reported to use SL as germination stimulant (Yokota et al., 1998). The particular structural specificity of having C-D ring moiety has been reported for stimulating germination of various weed species (Yoneyama et al., 2009). This property of SL can be exploited for better management of weeds. Developing chemical analogues of SL to induce suicide germination of the weed seeds and extensive breeding programme to develop cultivars emitting SL at lower level- can be followed for better exploitation of this novel phyto-hormone (Tsuchiya et al., 2010). Tsuchiya et al., 2010 reported a group of cell membrane permeable structurally similar small molecules as cotylemides (CTL) to increase endogenous SL level. Further analysis in Arabidopsis also led them to report that SL sensitize seed and seedlings to light adapted development by regulating the accumulation of the COP1 ubiquitin ligase, involved in light signaling. Strigolactone has both endogenous and exogenous activity in plant. It has been reported to inhibit axillary lateral meristem activity, thus regulating shoot branching as well as plant architecture (Gomez-Roldan et al. 2008; Umehara et al. 2008; Tsuchiya et al., 2010). Apart from auxin and cytokinin- two major hormones widely known to regulate shoot branching, SL can also be used for this purposes in tissue culture (Grobbellar, 2013) or commercially (Liang et al., 2010). While considering exogenous activity, it is largely involved in symbiotic relationship between arbuscullarmychorrhiza and their host and non-host species (Akiyama et al., 2005, Parniske, 2008). The structure-activity relationship of SLs as branching factors was extensively studied by Akiyama et al. (2010),Besserer et al. (2006). This phenomenon involves almost $80 \%$ species of plant kingdom (Tsuchiya et al., 2010). It has significant role during plant stress responses including drought stress, nutrient starvation, salinity, temperature and pathogen attack (Mishra S et al., 2017). Aroca et al. (2013) have suggested that salt stress induced strigolactone production in AM associated lettuce plants further triggers AM fungal growth and thus helps to overcome stress conditions. Ha et al (2014) reported positive regulation of salinity and drought response in Arabidopsis through mediation of SL. Strigolactone lowers the ABA to GA balance and increases cytokinin levels, which positively affects seed germination. Under high temperature stress, application of GR24 stimulates germination of SL defective Arabidopsis mutant (Tsuchiya et al., 2010). It has also been recognized as a compound to offer resistance to specific pathogens (Marzec, 2016). Besides phytohormones and other chemical compounds, SL level is also regulated by phosphate levels i.e., SL production increases in shortage of phosphate (Koltai., 2015).

\section{Karrikins}

Though chemicals in smoke were known to help in better germination in some fire follower species, the first active compound in smoke having the same activity was discovered after using sophisticated techniques i.e., gas chromatographymass spectrometry, and nuclear magnetic resonance during 2004 (Flematti et al., 2004). The first butenolide compound discovered in smoke water and its analogs were named as "karrikins" or KARs ("karik"- the word for smoke in Noongar Aboriginals' language of South-west Australia) (Waters M T, 2017). Karrikins show similarity with SL in having essential butenolide moiety for bioactivity (Flematti et al., 2009), germination stimulating activity (Flematti et al., 2004, Nelson et al., 2012). The report of response to KARs in Arabidopsis, a non- fire following species, became a boon for subsequent scientific discoveries (Nelson et al., 2009). The response to KARs in Arabidopsis in presence of Gas and light was similar as that of fire following species (Nelson et al., 2009), suggesting these compounds alone cannot overcome seed dormancy rather requires other components to stimulate seed germination (Merrit D et al., 2007; Long RL et al., 2011). The similarities in chemical structure of KARs and SL revealed various analogy and homology in many components of signaling pathways of these two hormones (Flematti et al., 2015; Morffy et al., 2016). KARs have inhibitory effect on 
hypocotyls elongation (Nelson et al., 2010, Waters and Smith 2013), enhance seedling photomorphogenesis by promoting cotyledon expansion and chlorophyll accumulation (Nelson et al., 2010). Hence, it can be hypothesized to be an efficient solution to alternate plant shade avoidance syndrome (Waters M. T., 2017). The effect of KARs with other hormones involved in germination i.e., GA and ABA was also studied. It was reported that, $A B A$ has negative effect on KAR activity while GA is needed for KAR to increase seed germination (Nelson et al., 2009). Considering another phytohormone Auxin, KARs suppress the expression of IAA response genes (Yang et al., 2004, Nelson et al., 2011; Gilkerson et al., 2015) and may also accelerate germination process by suppressing the signals of IAA. Apart from Arabidopsis and fire following species, KARs are reported to have various effect on seed germination activity of several crop species i.e., lettuce (Drewes et al., 1995), tomato (Jain et al., 2006), soybean (Meng et al.,2016) etc. Suicidal germination of agricultural weeds can be achieved through KAR treatment in soil, which will help eliminate weeds easily (Flematti et al., 2015). Waters M. T. (2017) has suggested the reduction of pre-harvest sprouting of soybean by spraying KARs solution on mother plant, as it has inhibitory effect on soybean seed germination. Study on effects of KARs on important crop species i.e., rice, wheat, maize, pulses etc. should be of greater interest. There remains various interacting pathways and further cross-talks of other hormones with KARs to be elucidated which will enhance its importance as a potent novel plant growth regulator.

\section{Harzianolide}

Harzianolide was discovered from cultures of the fungus Trichoderma harzianum during the studies on metabolites of this bio-control agent and was shown to be 3- (2'hydroxypropyl)-4-(hexa-2', 4'- dienyl)- 2(15H)- furanone, by NMR methods (Claydon et al., 1991). Till date it has been isolated from three different strains of $T$. harzianum (Almasi F et al., 1991; Claydon et al., 1991; Ordentlich A et al., 1992). A study about bioactivity of this compound by Cai et al (2013) revealed its role in both plant growth promotion and systemic resistance induction. The results showed a significant increase in growth of tomato seedlings by up to 2.5-fold (dry weight) at a $0.1 \mathrm{ppm}$ concentration of harzianolide while compared with the control. It also influences early stages of plant growth through better root development. This novel metabolite has been reported to enhance seedling growth in tomato, canola, wheat and show an auxin like activity on etiolated pea stems (Vinale et al., 2006; 2008). It can act as auxin like compounds which show dose dependent activity (Cai et al, 2013). Various metabolic products of the $T$. harzanium strain are involved in different biotic as well as abiotic stress responses (Vishevetsky et al., 2011; Samolski et al., 2012; Rana et al., 2012; Calo et al.., 2006; Dana yet al., 2006). Again different studies have been done regarding role of harzianolide in inducing the expression of the genes involved in the salicylic acid, jasmonate/ ethylene signaling pathway (Cai et al., 2013; Vinale et al., 2008). Hence, the role of harzianolide in regulation of biotic and abiotic stress management by influencing different hormonal signaling pathway can be studied extensively. The role of this novel metabolite as plant growth regulator still provides a vast area of exploration.

\section{Conclusion}

Role of SL in various stress tolerance should be more exploited more. Likewise, a clear concept of mode of action of serotonin and melatonin still needs further investigations. Role of these hormones in stress management along with interaction with other hormones as well as signaling pathway should be the focus of study. An unexploited arena of research is karrikins and harzianolide as potent plant growth regulators, still remains to be untangled. This may lead to develop stress tolerant cultivars with high yielding ability.

\section{References}

Afreen, F., Zobayed,SMA., Kozai, T., 2006. Melatonin in Glycyrrhizauralensis: response of plant roots to spectral quality of light and UV-B radiation. Journal of PinealResearch 41, 108-115.

Almassi, F., Ghisalberti, E.L., Narbey, M.J., Sivasthamparam, K., 1991. New antibiotics from strains of Trichoderma harzianum. Journal of Natural Products 54, 396-402.

Arnao, M.B., Hernandez-Ruiz, J., 2007. Melatonin promotes adventitious- andlateral root regeneration in etiolated hypocotyls of Lupinus albus L. Journal of Pineal Research 42, 147-152.

Arnao, M.B., Hernandez-Ruiz, J., 2006. The physiological function of melatoninin plants. Plant Signal Behav 1, 89-95.

Arnao, M.B., Herna'ndez-Ruiz, J., 2009. Protective effect of melatonin against chlorophyll degradation during the senescence of barley leaves. Journal of Pineal Research 46, 58-63.

Arnao, M.B.,Herna'ndez-Ruiz, J., 2009. Chemical stress by different agents affects the melatonin content of barley roots. Journal of Pineal Research 46, 295-299.

Arnao, MB.,Herna'ndez-Ruiz, J., 2013. Growth conditions influence the melatonin content of tomato plants. Food Chemistry 138, 1212-1214.

Arnao, M.B.,Herna'ndez-Ruiz, J., 2013. Growth conditions determine different melatonin levels in Lupinus albus L. Journal of Pineal Research 55, 149-155.

Avent, A.G., Hanson, J.R., Trunch, A., 1992. The biosynthesis of Harzianolide by Trichoderma harzianum. Phytochemistry 31, 3, 791-793.

Boccalandro, H.E., Gonzalez, C.V., Wunderlin, D.A., Silva, M.F., 2011. Melatonin levels, determined by LC-ESI-MS/MS, fluctuate during the day/night cycle in Vitis viniferacv Malbec: evidence of its antioxidant role in fruits. Journal of Pineal Research 51, 226-231. 
Byeon, Y., Park, S., Kim, Y.S, Back, K., 2013. Microarray analysis of genes differentially expressed in melatoninrich transgenic rice expressing a sheep serotonin $\mathrm{N}$-acetyltransferase. Journal of Pineal Research 55, 357-363.

Byeon, Y., Park, S., Kim, Y.S., Park, D.H., Lee, S., 2012. Lightregulated melatonin biosynthesis in rice during the senescence process in detached leaves. Journal of Pineal Research 53, 107-111.

Cai, F., Yu, G., Wang, P., Wei, Z., Fu, L., Shen, Q., Chen, W., 2013. Harzianolide, a novel plant growth regulator and systemic resistance elicitor from Trichoderma harzianum. http://dx.doi.org/10.1016/j.plaphy.2013.08.011.

Calo, L., Garcia, I., Gotar, C., Romero, L.C., 2006. Leaf hairs influence phytopathogenic fungus infection and conferred an increased resistance expressing a Trichoderma 1, 3-glucanone. Journal of Experimental Botany 50, 3911-3920.

Chen, Q., Qi, W., Reite,r R., Wei, W., Wang, B., 2009. Exogenously applied melatonin stimulates root growth and raises endogenous IAA in roots of etiolated seedling of Brassica juncea. J Plant Physiol 166, 324-328.

Claydon, N., James, R.H., Trunch, A., Avent, A.G., 1991. Harzianolide, A butenolide metabolite from cultures of Trichoderma harzianum. Phytochemistry 30, 11, 3803-3805.

Cook, C.E., Whichard, L.P., Turner, B., Wall, M.E., Egley, G.H., 1966. Germination of witchweed (Striga lutea Lour.): isolation and properties of a potent stimulant. Science 154, 1189-1190.

Dana, M., Pintor-Toro, J.A., Cubero, B., 2006. Transgenic tobacco plants overexpresingchitinases of fungal origin show enhanced resistance to biotic and abiotic stress agents. Plant Physiology 142, 722-730.

Drewes, F., Smith, M., van Staden, J., 1995. The effect of a plant- derived smoke extract on the germination of light sensitive lettuce seed. Plant Growth Regulator 16, 205-109.

Erland, L.A.E., 2016. Serotonin: An ancient molecule and an important regulator of plant processes, BiotechnolAdvhttp://dx.doi.org/10.1016/j. biotechadv.2016.10.002.

Flematti, G.R., Ghisalberti, E.L., Dixon, K.W., Trengove, R.D., 2004. A compound from smoke that promotes seed germination.Science 305, 977. Doi: 10.1126/science, 1099944.

Flematti, , G.R., Ghisalberti, E.L., Dixon, K.W., Trengove, R.D., 2009. Identification of alkyl substituted $2 \mathrm{H}$ - Furo [2,3c] pyran-2-ones as germination stimulants present in smoke. Journal of Agricultural and Food Chemistry. 57. 9475-9480. doi: 10.1021/jf9028128.

Flematti, G.R., Dixon, K.W., Smith, S.M., 2015. What are Karrikins and how were they 'discovered' by plants? BMC Biology. 13:1.doi:10.1186/s12915-015-0219-0.
Gilkerson, J., Kelley, D.R., Tam, R., Estelle, M., Callis, J., 2015. Lysine residues are not required for proteoasomemediated proteolysis of the Auxin/ indole acetic acid protein IAA1. Plant Physiology. 168: 708-720. doi:10.1104/pp.15.00402.

Hauck, C., Muller, S., Schildknecht, H., 1992. A germination stimulant for parasitic flowering plants from Sorghum bicolor, a genuine host plant. Journal of Plant Physiology 139, 474-478.

Herna'ndez-Ruiz, J., Arnao, M.B., Cano, A., 2004. Melatonin: growth-stimulating compound present in lupin tissues. Planta 220, 140-144.

Herna'ndez-Ruiz, J., Cano, A., Arnao, M.B., 2005. Melatonin acts as a growth-stimulating compound in some monocot species. Journal of Pineal Research 39, 137-142.

Hernandez-Ruiz, J., Arnao, M.B., 2008. Melatonin stimulates the expansion of etiolated lupin cotyledons. Plant Growth Regulation 55, 29-34.

Hernandez-Ruiz, J., Arnao, M.B., 2008. Distribution of melatonin in different zones of lupin and barley plants at different ages in the presence and absence of light. Joirnal of Agriculture and Food Chemistry 56, 1056710573.

Jain, N., Kulkarni, M.G., van Staden, J., 2006. A butenolide isolated from smoke, can overcome the detrimental effects of extreme temperatutres during tomato seed germination. Plant Growth Regulators 49, 263-267.

Kang, K., Lee, K., Park, S., Kim, Y.S., Back, K., 2010. Enhanced production ofmelatonin by ectopic overexpression of human serotonin $\mathrm{N}$-acetyltransferase plays a role in cold resistance in transgenic rice seedlings. Journal of Pineal Research 49, 176-182.

Kolar, J., Machackova, I., Eder, J., Prinsen, E., VanDongen, W., et al., 1997. Melatonin: occurrence and daily rhythm in Chenopodium rubrum. Phytochemistry 44, 1407-1413.

Kolar, J., Johnson, C.H., Macha'c kova, I., 2003. Exogenously applied melatonin affects flowering of the short-day plant Chenopodium rubrum. Journal of Pineal Research 118, 605-612.

Koltai, H., 2015. Cellular events of strigolactonesignalling and their crosstalk with auxin in roots. Journal of experimental botany 66, 4855-4861. doi:10.1093/jxb/ erv178.

Lei, X.Y., Zhu, R.Y., Zhang, G.Y., Dai, Y.R., 2004. Attenuation of cold-inducedapoptosis by exogenous melatonin in carrot suspension cells: the possibleinvolvement of polyamines. Journal of Pineal Research 36, 126-131.

Li, C., Wang, P., Wei, Z., Liang, D., Liu, C., 2012. The mitigation effects of exogenous melatonin on salinity-induced stress in Malus hupehensis. Journal of Pineal Research 53, 298-306.

Long, R.L., Stevans, J.C., Griffith, E.M., Adamek, M., Gorechi, M.J., Powles, S.B., Merrit, D.J., 2011. Seeds 
of Brassicaceae weeds have an inherent or inducible reponse to the germination stimulant Karrikinolide. Annals of Botany 108, 933-944.

Mark, T., Waters., 2017. From little things big things grow: Karrikins and new directions in plant development. Functional Plant Biology 44. 373-385. http;//dx.doi. org/10.1071/FPH6405.

Meng, Y., Chen, F., Shnai, H., Luo, X., Ding, J, Tang, S., 2016. Karrikins delay soybean seed germination by mediating abscisic acid and gibberellins biogenesis under shaded conditions. Scientific Reports, 6, 22073. Doi: 10.1038/ srep22703.

Merrit, D., Turner, S., Clarke, S., Dixon, K., 2007. Seed dormancy and germination stimulation syndrome for Australian temperate species.Australian Journal of Botany 55, 336-344.

Morffy, M., Faure, L., Nelson, D.C., 2016. Smoke and hormone mirrors: action and evolution of karrikin and strigolactone signaling. Trends in Genetics 32, 176-188. Doi: 10.1016/j.tig.2016.01.002.

Muller, S., Hauck, C., Schildknecht, H., 1992. Germination stimulants produced by Vigna unguiculataWalpcv Saunders Upright. Journal of Plant Growth Regulator 11, 77-84.

Murch, S.J., KrishnaRaj, S., Saxena, P.K., 2000. Tryptophan is a precursor formelatonin and serotonin biosynthesis in in vitro regenerated St John's wort (Hypericum perforatum L. cv. Anthos) plants. Plant Cell Reports 19, 698-704.

Murch, S., Saxena, P., 2002. Mammalian neurohormones: potential significance in reproductive physiology of St. John's wort (Hypericum perforatum L.). Naturwissenschaften 89, 555-560.

Nelson, D.C., Scaffidi, N., Dun, E.A., Waters, M.T., Flematti, G.R., Dixon, K.W., 2011. F-box protein MAX2 has dual roles in Karrikin and Strigolactone signaling in Araidopsis thaliana. Prac. National Academy of Sciences, USA 108, 8897-8902.

Nelson, D.C., Flemati, G.R., Riseborogh, J.A., Ghisalberti, E.L., Dixon, K.W., Smith, S.M., 2010. Karrikins enhance light responses during germination and seedling development in Arabidopsis thaliana. Proccedings of National Science, USA. 107, 7095-7100.

Nelson, D.C., Flematti, G.R., Ghisalberti, E.L., Dixon, K.W., Smith, S.M., 2012. Regulation of seed germination and seedling growth by chemical signals from burning vegetation.Annual review of Plant Biology 63 107-130.

Nelson, D.C., Riseborogh, J.A., Flematti, G.R., Stevens, J., Ghisalberti, E.C., 2009. Karrikins discovered in smoke trigger Arabidopsis seed germination by a mechanism regulating gibberellic acid synthesis and light. Plant Physiology 149, 863-873.

Ordentlich, A., Wiesman, Z., Gottleib, H.E., Lojocaru, M., Chef, J., 1992. Inhibitory furanone produced by the biocontrol agent Trichoderma harzianum. Phytochemistry 32,
485-486.

Paredes, S.D., Korkmaz, A., Manchester, L.C., Tan, D.X., Reiter, R.J., 2009. Phytomelatonin: a review. Journal of Experimental Boanyt 60, 57-69.

Park, S., Le, T.N.N., Byeon, Y., Kim, Y.S., Back, K., 2013. Transient induction of melatonin biosynthesis in rice (Oryza sativa L.) during the reproductive stage. Journal of Pineal Research 55, 40-45.

Park, S., Lee, D.E., Jang, H., Byeon, Y., Kim, Y.S., 2013. Melatonin-rich transgenic rice plants exhibit resistance to herbicide-induced oxidative stress. Journal of Pineal Research 54, 258-263.

Park, S., Back, K., 2012. Melatonin promotes seminal root elongation and rootgrowth in transgenic rice after germination. Journal of Pineal Research 53, 385-389.

Park, W.J., 2011. Melatonin as an endogenous plant regulatory signal: debatesand perspectives. Journal of Plant Biology 54, 143-149.

Rana, I.A., Lorez, H., Schaefer, W., Becker, D., 2012. Overexpression of chitinase and chitosanase genes from Trichoderma harzianum under constitutive and inducible promoters in order to increase disease resistance in wheat (Triticum aestivum L.). Molecular Plant Breeding 3, 37-49.

Samolski, I., Rineon, A.M., PinZon, L.M., Viterbo, A. Monte, E., 2012. The qid74 gene from Trichoderma harzianum has a role in root architecture and plant biofertilization. Microbiology 158, 129-138.

Sarropoulou, V., Dimassi-Theriou, K., Therios, I., KoukourikouPetridou M., 2012. Melatonin enhances root regeneration, photosynthetic pigments, biomass, total carbohydrates and proline content in the cherry rootstock PHL-C (Prunusavium $\times$ Prunuscerasus). Plant PhysiolBiochem 61, 162-168.

Siame, B.P., Weerasuriya, Y., Wood, K., Ejeta, G., Butler, L.G., 1993. Isolation ofstrigol, a germination stimulant for Strigaasiatica, from host plants. Journal of Agriculture and Food Chemistry 41, 1486-1491.

Tan, D., Chen, L., Poeggeler, B., Manchester, L., Reiter, R., 1993. Melatonin: apotent, endogenous hydroxyl radical scavenger. Endocrine Journal 1, 57-60.

Tan, D., Mancheste, R.L., Terron, M., Flores, L., Reiter, R., 2007. One molecule, many derivates: A never-ending interaction of melatonin with reactive oxygen and nitrogen species? Journal of Pineal Research 42, 28-42.

Tan, D.X., Manchester, L.C., Di Mascio, P., Martinez, G.R., Prado, F.M., 2007. Novel rhythms of N-1-acetyl-N-2-formyl-5methoxykynuramine and its precursor melatonin in water hyacinth: importance for phytoremediation. FASEB Journal 21, 1724-1729.

Tan, D.X., Reiter, R.J., Manchester, L.C., Yan, M.T., El-Sawi, M., 2002. Chemical and physical properties and potential mechanisms: melatonin as a broad spectrum antioxidant and free radical scavenger. Current Topics in Medicinal 
Chemistry 2, 181-197.

Tan, D.X., Manchester, L.C., Helton, P., Reiter, R.J., 2007. Phytoremediative capacity of plants enriched with melatonin. Plant Signaling and Behavior 2, 514-516.

Tsuchiya, Y., Vidaurre, D., Toh, S., Hanada, A., Nambara, A., Kamiya, Y., 2010. A small molecule screen identifies new functions for the plant hormone strigolactone. Nature Chemical Biology DOI: 10.1038/NCHEMBIO, 435-597.

Van Tassel, D.L., Roberts, N., Lewy, A., O'Neill, S.D., 2001. Melatonin in plant organs. Journal of Pineal Research 31, 8-15.

Vinale, F., Marra, R., Scala, F., Ghisalberti, E.L., Lorito, M., 2006. Major secondary metabolites produced by two commercial Trichoderma strains active against different phytopathogens. Lett. Appl. Microbiol 43, 143-148.

Vinale, F., Sivasthamparam, K., Ghisalberti, E.L., 2008. A novel role for Trichoderma secondary metabolites in the interaction with plants. Physiological and Molecular plant pathology 72, 80-86.

Vishnevetsky, J., Hwite, T.L., Palmateer, A.J., Flashman, M., 2011. Improved tolerance towards fungal diseases in transgenic Cavendish banana (Musa spp. AAA) cv. Grand Nain. Transgenic Research 20, 61-72.

Wang, P., Sun, X., Li, C., Wei, Z.W., Liang, D., 2013. Long-term exogenous application of melatonin delays droughtinduced leaf senescence in apple. Journal of Pineal Research 54, 292-302.

Wang, P., Yin, L., Liang, D., Li, C., Ma, FW., 2012. Delayed senescence of apple leaves by exogenous melatonin treatment: toward regulating the ascorbate-glutathione cycle. Journal of Pineal Research 53, 11-20-23.

Waters, M.T., Smith, S.M., 2013. KAI2 and MAX2 madiated responses to Karrikins and Strigolactones are largely independent of HY5 in Arabidopsis seedlings. Mol. Plant. 6, 63-75. Doi: 10.1093/mp/sss127.
Yang, X., LC, S., Su, J.H., Dharmasiri, S., Dharmasiri, H., 2004. The IAA1 protein is encoded by AXR5 and is a substrate of SCFTIR1. Plant J. 40:772-782.

Yin, L., Wang, P., Li, M., Ke, X.W., Li, C.Y., 2013. Exogenous melatonin improves Malus resistance to Marssonina apple blotch. Journal of Pineal Research 54, 426-434.

Yokota, T., Sakai, H., Okuno, K., Yoneyama, K., Takeuchi, Y., 1998. Alectrol and orobanchol, germination stimulants for Orobanche minor, from its host red clover. Phytochemistry 49, 1967-1973.

Yoneyama, K., Xie, X., Yoneyama, K., Takeuchi, Y., 2009. Strigolactones:structures and biological activities. Pest Management Science DOI 10.1002/ps.1726

Zhao, Y., Tan, DX., Lei, Q., Chen, H., Wang, L., 2012. Melatonin and its potential biological functions in the fruits of sweet cherry. Journal of Pineal Research 55, 79-88.

Zhang, L., Jia, J., Xu, Y., Wang, Y., Hao, J., 2012. Production of transgenic Nicotianasylvestris plants expressing melatonin synthetase genes and their effect on UV-Binduced DNA damage. In vitro cellular \& developmental biology. Plant 48, 275-282.

Zhang, N., Zhao, B., Zhang, H. J., Weeda, S., Yang, C., 2013. Melatonin promotes water-stress tolerance, lateral root formation, and seed germination in cucumber (Cucumis sativus L.). Journal of Pineal Research 54, 15

Zhang, L., Jia, J., Xu, Y., Wang, Y., Hao, J., 2012. Production of transgenicNicotianasylvestris plants expressing melatonin synthetase genes and their effecton UV-Binduced DNA damage. In vitro cellular \& developmental biology.Plant 48, 275-282. 